Fabiano Séllos COSTA ${ }^{1}$

Mauro José Lahm

$\mathrm{CARDOSO}^{2}$

Lucy Marie Ribeiro MUNIZ ${ }^{3}$

Luiz Carlos VULCANO ${ }^{3}$

Warley Gomes dos

SANTOS $^{1}$

Carlos Roberto PADOVANI ${ }^{4}$

Correspondência para:

Prof. Adj. Dr. Fabiano Séllos Costa, fabianosellos@hotmail.com, Universidade Federal do Espírito Santo, Centro de Ciências Agrárias - Departamento de Medicina Veterinária, Alto Universitário $\mathrm{s} / \mathrm{n}$, Alegre-ES, 29500-000

Recebido para publicação: 15/07/2006 Aprovado para publicação: 12/03/2009

\title{
Correlação entre a densidade mineral óssea e níveis séricos de cálcio, fósforo e fosfatase alcalina total em gatos após tirotoxicose experimental
}

\author{
1 - Departamento de Medicina Veterinária do Centro de Ciências Agrárias da \\ Universidade Federal do Espírito Santo, Alegre - ES \\ 2 - Fundação Faculdades Luiz Meneghel/Universidade Estadual do Paraná, \\ Bandeirantes - PR \\ 3 - Departamento de Reprodução Animal e Radiologia Veterinária da Faculdade de \\ Medicina Veterinária e Zootecnia da Universidade Estadual Paulista, Botucatu - SP \\ 4 - Departamento de Bioestatística do Instituto de Biociências da Universidade \\ Estadual Paulista, Botucatu - SP
}

\section{Resumo}

O hipertiroidismo é caracterizado por concentrações séricas excessivas dos hormônios tiroidianos, podendo causar efeitos sobre o tecido ósseo em humanos e animais. Para melhor caracterização dos efeitos da tirotoxicose no metabolismo ósseo, 16 gatos foram induzidos ao estado hipertiroideo. Os resultados demonstraram que, em alguns momentos experimentais, uma maior desmineralização óssea da extremidade distal do rádio promoveu elevação dos níveis séricos de fósforo e fosfatase alcalina total.

\section{Introdução}

O hipertiroidismo felino é uma alteração clínica multissistêmica resultante das excessivas concentrações dos hormônios tiroidianos, sendo atualmente considerado o distúrbio endócrino de maior freqüência nos gatos domésticos. . $^{1,2,3,4}$

O excesso de hormônios tiroidianos (tirotoxicose) é caracterizado por manifestações clínicas que podem gerar sintomatologia com gravidade variável, sendo este fato dependente do estágio em que a doença se encontra e da coexistência de outras afecções sistêmicas. ${ }^{5}$

No homem, o hipertiroidismo é capaz de provocar osteopenia podendo evoluir para osteoporose como conseqüência de um aumento da taxa de reabsorção óssea. A reposição hormonal excessiva em mulheres com hipotiroidismo, principalmente após a menopausa, pode produzir um estado hipermetabólico idêntico ao observado na tirotoxicose endógena, podendo ter como seqüela um remodelamento ósseo exagerado, associado ao aumento dos níveis séricos de cálcio, fósforo e fosfatase alcalina. ${ }^{6,78}$ Este fato assume destacada importância, uma vez que os hormônios da tiróide estão entre as medicações mais prescritas na medicina humana e a administração de uma dose acima da recomendada pode ocasionalmente ser encontrada. ${ }^{6}$

Nos animais domésticos, os hormônios tiroidianos também podem proporcionar graves efeitos no tecido ósseo e a ocorrência de fraturas patológicas é uma manifestação clínica possível. ${ }^{9}$ Associado a este fato, a avaliação bioquímica sérica dos gatos acometidos com esta enfermidade pode revelar hiperfosfatasemia, hipercalcemia ${ }^{10,11,12} \mathrm{e}$ hiperfosfatemia?.

O hipertiroidismo pode influenciar no metabolismo do cálcio aumentando a atividade osteoclástica e proporcionando uma reabsorção óssea acentuada, podendo ser também caracterizado um decréscimo da absorção intestinal de cálcio e hipercalciúria. Entretanto, a maioria dos pacientes humanos tende a apresentar valores séricos de cálcio dentro dos padrões de 
normalidade. $^{12}$

O aumento da retirada de cálcio do tecido ósseo induz, de forma compensatória, ao decréscimo na secreção de paratormônio, na tentativa de manter os níveis séricos normais. ${ }^{3,13}$ Este fato aumenta a taxa de reabsorção tubular de fosfato, podendo ser o fator mais importante para justificar o aumento sérico nos níveis de fósforo. Entretanto, um aumento na mobilização do fósforo de origem óssea e dos tecidos moles também pode contribuir para a hiperfosfatasemia. ${ }^{13}$

A fosfatase alcalina sérica total é constituída pela contribuição de diferentes isoenzimas, podendo este aumento estar comumente correlacionado a alterações no tecido ósseo, fígado, placenta e intestino. ${ }^{10,14,15,16,17,18} \mathrm{O}$ aumento da atividade osteoblástica, promovido pela ação dos hormônios tiroidianos, é considerada como causa freqüente de hiperfosfatasemia ${ }^{15,17}$, sendo descrita uma correlação entre estes achados e uma desmineralização óssea em humanos ${ }^{17}$. Entretanto, alterações hepáticas decorrentes de um estado de tirotoxicose também podem contribuir para este acontecimento. ${ }^{1,19}$

Protocolos de indução à tirotoxicose foram desenvolvidos para melhor caracterização da doença. Estudos experimentais em $\operatorname{ratos}^{20,21}$, cães $^{22} \mathrm{e}$ humanos ${ }^{23}$ foram eficazes para promover uma elevação dos níveis séricos dos hormônios tiroidianos, sendo possível a demonstração de efeitos no metabolismo ósseo destas espécies.

O objetivo deste estudo foi induzir ao estado de tirotoxicose experimental, gatos hígidos, e correlacionar, nos diferentes momentos, a densidade mineral óssea (DMO) da extremidade distal do rádio direito com os valores séricos de cálcio, fósforo e fosfatase alcalina total.

\section{Material e Método}

Foram utilizados 16 gatos domésticos (Felis catus, L. 1758), adultos, sem distinção de sexo ou raça e sem alterações clínicas ou laboratoriais que pudessem interferir na realização da pesquisa. Animais em fase de crescimento, idosos, castrados e fêmeas gestantes foram excluídos do grupo experimental. Após a seleção, os animais foram alojados em um gatil com acesso ao sol, sendo administrada alimentação (ração seca) e água à vontade. Para indução ao estado de tirotoxicose, administrou-se por via oral $150 \mu \mathrm{g} / \mathrm{kg}$ de levotiroxina sódica na forma de comprimidos, a cada 24 horas durante 42 dias consecutivos. Após este período experimental, foi finalizada a administração do fármaco levotiroxina sódica e os animais ficaram por 10 dias sob observação, e após este tempo, foram doados. As avaliações das variáveis densidade mineral óssea (DMO), tiroxina livre e total (T4 livre e T4 total), cálcio, fósforo e fosfatase alcalina (FA) foram mensuradas anteriormente ao início do protocolo experimental, sendo repetidas semanalmente até o término da administração hormonal, constituindo sete momentos experimentais.

A determinação da DMO da extremidade distal do rádio direito foi realizada em todos os momentos pela técnica de densitometria óptica em imagens radiográficas, conforme metodologia descrita por Louzada ${ }^{24}$ e adaptada por Vulcano ${ }^{25}$. Foram realizados três exames radiográficos na projeção crânio-caudal do membro torácico direito de todos os animais em cada momento experimental, abrangendo a região de extremidade distal do rádio. As radiografias foram realizadas utilizando-se uma kilovoltagem fixa de $35 \mathrm{kVp}$ e a miliamperagem e o tempo de exposição à radiação foram ajustados de acordo com a necessidade individual de cada animal ao primeiro exame. Desta forma, o valor da DMO da região selecionada foi obtido em mmAL por meio da média aritmética das três mensurações.

Para o estudo dos parâmetros avaliados ao longo dos sete momentos experimentais, foi realizada a análise de variância de medidas repetidas e, para as associações utilizou-se o coeficiente de 
correlação linear de Pearson. Quando a variável apresentou características de distribuição normal de probabilidade, o procedimento utilizado foi paramétrico e, na ausência de características de distribuição normal, utilizaram-se testes estatísticos nãoparamétricos.

\section{Resultados}

O protocolo de indução ao estado hipertiroideo utilizado foi eficaz para gatos, sendo caracterizada a elevação dos níveis séricos de T4 livre e T4 total com significância estatística. Esse aumento esteve presente a partir da primeira semana de administração oral de levotiroxina sódica, mantendo-se alto os níveis hormonais até o término do período experimental. Também foi possível demonstrar uma desmineralização óssea da extremidade distal do rádio a partir do sétimo dia de administração hormonal. Presenciou-se também uma elevação dos níveis séricos de fosfatase alcalina total com 14 dias de experimento. Não foi caracterizada alteração estatisticamente significativa ao nível de 5\% de significância nos valores séricos de cálcio e fósforo (Tabela 1).

As variáveis DMO e fósforo apresentaram características de distribuição normal de probabilidade, utilizando-se procedimento paramétrico (significâncias indicadas por letras minúsculas ao lado das médias). Entretanto as variáveis, T4 livre, T4 total, cálcio e fosfatase alcalina não apresentaram características de distribuição normal de probabilidade, sendo adotado procedimento não-paramétrico (significâncias indicadas por letras minúsculas ao lado das medianas).

$\mathrm{Na}$ segunda, quarta e quinta semana de administração hormonal foi constatada correlação negativa $(p<0,05)$ entre os valores séricos de fósforo e os valores densitométricos. $\mathrm{Na}$ quarta semana de experimento se presenciou uma forte correlação negativa $(p<0,01)$ entre os valores séricos de fosfatase alcalina total e valores de DMO, indicando uma maior atividade desta enzima nos animais com uma desmineralização óssea mais significativa. Em nenhum momento experimental foi presenciada a correlação estatisticamente significativa entre os valores séricos de cálcio e DMO (Tabela 2).

\section{Discussão e Conclusões}

Assim como neste estudo, diversos autores conseguiram promover uma indução experimental à tirotoxicose a partir da administração oral de levotiroxina sódica, possibilitando melhor compreensão dos aspectos fisiopatológicos desta enfermidade..$^{20,21,22,23}$ No homem, pode-se promover quadro hipermetabólico iatrogênico e alterações ósseas similares ao hipertiroidismo endógeno ${ }^{6}$ com a suplementação excessiva dos hormônios

Tabela 1 - Medidas descritivas das variáveis avaliadas ao longo dos sete momentos experimentais (42 dias) em gatos com tirotoxicose induzida - Botucatu - 2006

\begin{tabular}{cccccccc}
\hline Variáveis & M0 & Ml & M2 & M3 & M4 & M5 & M6 \\
\hline T4 livre $(\mathbf{n g} / \mathbf{d l})$ & $0,31 \mathrm{a}$ & $0,79 \mathrm{~b}$ & $1,09 \mathrm{~b}$ & $0,93 \mathrm{~b}$ & $1,09 \mathrm{~b}$ & $1,04 \mathrm{~b}$ & $0,71 \mathrm{~b}$ \\
T4 total $(\mu \mathrm{g} / \mathrm{dl})$ & $2,43 \mathrm{a}$ & $6,09 \mathrm{~b}$ & $6,27 \mathrm{~b}$ & $8,27 \mathrm{~b}$ & $7,92 \mathrm{~b}$ & $9,79 \mathrm{~b}$ & $7,16 \mathrm{~b}$ \\
DMO $(\mathbf{m m A l})$ & $1,43 \mathrm{~b}$ & $1,38 \mathrm{a}$ & $1,38 \mathrm{a}$ & $1,35 \mathrm{a}$ & $1,35 \mathrm{a}$ & $1,34 \mathrm{a}$ & $1,33^{\mathbf{a}}$ \\
Cálcio $(\mathbf{m g} / \mathbf{d l})$ & $9,75 \mathrm{a}$ & $9,80 \mathrm{a}$ & $9,75 \mathrm{a}$ & $9,80 \mathrm{a}$ & $9,90 \mathrm{a}$ & $9,90 \mathrm{a}$ & $9,85^{\mathbf{a}}$ \\
Fósforo $(\mathbf{m g} / \mathbf{d l})$ & $6,12 \mathrm{a}$ & $6,33 \mathrm{a}$ & $6,42 \mathrm{a}$ & $6,40 \mathrm{a}$ & $6,40 \mathrm{a}$ & $6,18 \mathrm{a}$ & $6,51 \mathbf{a}$ \\
FA (U/L) & $45,0 \mathrm{a}$ & $47,5 \mathrm{a}$ & $53,0 \mathrm{bc}$ & $56,5 \mathrm{c}$ & $70,0 \mathrm{~d}$ & $68,0 \mathrm{~d}$ & $51,5 \mathrm{~b}$
\end{tabular}

DMO - densidade mineral óssea, FA - fosfatase alcalina. Valores das médias ou medianas seguidas pelo menos de uma mesma letra não diferem ao nível de $5 \%$ de significância 
Tabela 2 - Medidas de associação entre a densidade mineral óssea e níveis séricos de cálcio, fósforo e fosfatase alcalina total ao longo dos sete momentos experimentais (42 dias) em gatos com tirotoxicose induzida - Botucatu - 2006

\begin{tabular}{cccccccc}
\hline $\begin{array}{c}\text { Associação entre } \\
\text { as variáveis }\end{array}$ & M0 & M1 & M2 & M3 & M4 & M5 & M6 \\
\hline DMO x Cálcio & 0,15 & 0,20 & $-0,06$ & $-0,08$ & $-0,04$ & $-0,02$ & $-0,17$ \\
DMO Fósforo & $-0,21$ & $-0,50^{*}$ & $-0,23$ & $-0,51^{*}$ & $-0,54^{*}$ & $-0,24$ & $-0,37$ \\
DMO $\mathbf{F A}$ & 0,17 & $-0,37$ & $-0,12$ & $-0,61^{* *}$ & $-0,28$ & $-0,50^{*}$ & $-0,35$ \\
\hline
\end{tabular}

${ }^{88} \mathrm{p}<0,01 ;{ }^{2} \mathrm{p}<0,05 . \mathrm{DMO}-$ dens idade mineral ós sea, FA - fosfatas e alcaling

tiroidianos em pacientes hipotiroideos. Deste modo, inferimos que protocolos de indução, tanto em gatos como em outras espécies, podem caracterizar as possíveis alterações do metabolismo ósseo.

Como a fosfatase alcalina total é resultante do somatório das atividades das isoenzimas derivadas de diferentes tecidos do organismo $^{10,14,15,16,17,18}$, fica impossibilitado afirmar qual a origem precisa da hiperfosfatasemia caracterizada nesta pesquisa. $\mathrm{O}$ mecanismo que leva ao aumento da atividade da fosfatase alcalina total em humanos com tirotoxicose ainda não está elucidado, porém, existem relatos que demonstram claramente aumento da atividade de isoenzima de origem óssea. ${ }^{10,15,17,18}$ A correlação presente entre a DMO do rádio e níveis séricos de fosfatase alcalina total nos gatos com tirotoxicose induzida, observada neste estudo, também sugere uma ação dos hormônios tiroidianos sobre o metabolismo ósseo. Deste modo, o acometimento hepático também é possível, uma vez que é citado que os exames histológicos do fígado de gatos hipertiroideos podem apresentar alterações normalmente modestas e inespecíficas, incluindo aumento de pigmentos nos hepatócitos, presença de células inflamatórias mistas em região portal e áreas focais de degeneração gordurosa. ${ }^{1}$ Em humanos com hipertiroidismo o acometimento do fígado também é descrito, entretanto, uma disfunção deste órgão é considerada rara, e os achados histopatológicos são discretos, inespecíficos e não apresentam correlação com a gravidade da doença. ${ }^{19}$

Apesar do aumento do fósforo sérico não ser um achado freqüente em gatos com hipertiroidismo endógeno, este fato normalmente é associado a animais idosos com insuficiência renal associada. ${ }^{5}$ Entretanto, o grupo de animais avaliados era constituído de gatos adulto-jovens e não apresentaram insuficiência renal durante o período experimental. Desta forma, significativa correlação negativa observada entre a DMO e as concentrações séricas de fósforo neste experimento sugere que assim como em outros estudos, a ação dos hormônios tiroidianos em excesso promove variações nos níveis séricos de fósforo.

A ausência de correlação negativa com significância estatística entre a DMO e o cálcio sérico observado em nossos resultados, pode estar correlacionada à diminuição da secreção do paratormônio pelos animais, na tentativa de manter a normocalcemia. Este fato também é sugerido por Peterson et al. ${ }^{3}$, onde 131 gatos com hipertiroidismo endógeno foram avaliados e nenhum apresentou hipercalcemia na avaliação bioquímica sérica.

Conclui-se que o protocolo de indução experimental à tirotoxicose utilizado foi eficaz e promoveu elevação dos níveis séricos dos hormônios tiroidianos a partir da primeira semana de administração do fármaco levotiroxina sódica. Conclui-se também que, nos animais avaliados, a perda de massa óssea proporcionada esteve, em alguns momentos, correlacionada estatisticamente com a elevação dos valores séricos de fósforo e fosfatase alcalina total. 


\title{
Correlation of bone mineral density and serum levels of calcium, phosphorus and alkaline phosphatase in cats after experimental thyrotoxicosis
}

\begin{abstract}
Hyperthyroidism is and endocrinal dysfunction characterized by excessive serum concentrations of thyroid gland hormones, which can cause several effects on the bone tissue in humans and in animals. For a better characterization of thyrotoxicosis effects on bone metabolism, 16 cats were induced into hyperthyroid state. Results showed that, in some moments a major bone demineralization of the right distal radium estremity promoted an elevation of the serum levels of phosphorus and total alkaline phosphatase.
\end{abstract}

\section{Referências}

1 FELDMAN, E. C.; NELSON, R. W. Canine and feline endocrinology and reproduction. Philadelphia: W.B. Saunders, 1996. 785 p.

2 MOONEY, C. T. Hyperthyroidism. In: ETTINGER, S. J.; FELDMAN, E. C. Textbook of veterinary internal medicine: diseases of the dog and cat. 6.ed. St. Louis: Elsevier Saunders, 2005. p. 1544-1560.

3 PETERSON, M. E.; KINTZER, P. P.; CAVANAGH, P. G.; FOX, P. R.; FERGUSON, D. C.; JOHNSON, G. F.; BECKER, D. V. Feline hyperthyroidism: pretreatment clinical and laboratory evaluation of 131 cases. Journal of the American Veterinary Medical Association, v. 183, n. 1, p. 103-110, 1983.

4 THODAY, K. L.; MOONEY, C. T. Historical, clinical and laboratory features of 126 hyperthyroid cats Veterinary Records, v. 131, n. 2, p. 257-264, 1992.

5 BROUSSARD, J. D.; PETERSON, M. E.; FOX, P. R. Changes in clinical and laboratory findings in cats with hyperthyroidism from 1983 to 1993. Journal of the American Veterinary Medical Association v. 206, n. 3, p.302-305, 1995

6 FALLON, M. D.; PERRY, H. M.; BERGFELD, M. DROKE, D.; TEITELBAUM, S. L.; AVIOLI, L. V.; Exogenous hypethyroidism with osteoporosis. Archives of Internal Medicine, v. 143, p. 442-444, 1983.

7 FOLDES, J.; TARJAN, G.; SZATHMARI, M.; KRASZNAI, I.; HORVATH, C. Bone mineral density in patients with endogenous subclinical hyperthyroidism: is this thyroid status a risk factor for osteoporosis? Clinical Endocrinology, v. 39, n. 5, p. 521-527, 1993.

8 JODAR, E.; TORRES, M. M.; JIMÉNES, F. E.; CHARNECO, M. Q.; CASTILLO, J. D. L. Bone loss in hyperthyroid patients and in former hyperthyroid patients controlled on medical therapy: influence of etiology and menopause. Clinical Endocrinology, v. 47, n. 3, p. 279-285, 1997.

9 WASSERMAN, R. H. Ossos. In: SWENSON, M. J.
Fisiologia dos animais domésticos. 10. ed. Rio de Janeiro : Guanabara Koogan, 1988. p. 413-427.

10 ARCHER, F. J.; TAYLOR, S. M. Alkaline phosphatase bone isoenzyme and osteocalcin in the serum of hyperthyroid cats. Canadian Veterinary Journal, v. 37, n. 12 , p. $735-739,1996$

11 BARBER, P. J.; ELLIOT, J. Study of calcium homeostasis in feline hyperthyroidism. Journal of Small Animal Practice, v.37, n. 12, p.575-582, 1996.

12 BEIGEL, Y.; ARIE, R.; WYSENBEEK, A. J.; HALABE, E.; BLUM, I. Hypocalcaemia, a possible manifestation of thyrotoxicosis. Postgraduate Medical Journal, v. 59 p. 317-319, 1983.

13 MOSEKILDE, L.; ERIKSEN, E. F.; CHARLES, P. Effects of thyroid hormones on bone and mineral metabolism. Endocrinology and Metabolism Clinics of North America, v. 19, n. 1, p. 35-63, 1990.

14 EVERETT, R. M.; DUNCAN, J. R.; PRASSE, K. W. Alkaline phosphatases in tissues and sera of cats. American Journal of Veterinary Research, v. 38, n. 10, p. 1533-1538, 1997.

15 FOSTER, D. J.; THODAY, K. L. Tissue sources of serum alkaline phosphatase in 34 hyperthyroid cats: a qualitative and quantitative study. Research in Veterinary Science, v. 68, n. 1, p. 89-94, 2000.

16 HORNEY, B. S.; FARMER, A. J.; MACKENSIE, A.; HONOR, D. J.; BUCZKOWSKI, S. Alkaline phosphatase isoenzymes in feline serum using an agarose gel alkaline phosphatase kit method. Canadian Journal of Veterinary Research, v. 56, n. 4, p. 373375, 1992.

17 RHONE, D. P.; BERLINGER, F. G.; WHITE, F. M. Tissue sources of elevated serum alkaline phosphatase activity in hyperthyroid patients. American Journal of Clinical Pathology, v. 34, p. 381-386, 1980.

18 TIBI, L.; PATRICK, A. N.; LESLIE, P.; TOFT, A. D.; SMITH, A. F. Alkaline phosphatase isoenzymes in plasma in hyperthyroidism. Clinical Chemistry, v. 35, n. 7 , p. $427-430,1989$ 
19 KLION, F. M.; SEGAL, R.; SCHAFFNER, F. The effect of altered thyroid function on the ultrastructure of the human liver. American Journal of Medicine, $v$. 50, n. 3, p. 317-324, 1971.

20 KUNG, A. W.; NG, F. A rat model of thyroid hormone-induced bone loss: effect of antiresorptive agents on regional bone density and osteocalcin gene expression. Thyroid, v. 4, n. 1, p. 93-98, 1994.

21 SERAKIDES, R.; NUNES, V. A.; NASCIMENTO, E. F. Relação tireóide-gônadas e níveis plasmáticos de fósforo, cálcio e fosfatase alcalina em ratas. Arquivos Brasileiros de Medicina Veterinária e Zootecnia, v. 52, n. 6, p. 579585, 2000.

22 ADAMS, P.; JOWSEY, J. Bone and mineral metabolism in hyperthyroidism: an experimental study. Endocrinology, v. 81, n. 4, p. 735-740, 1967.
23 LUKENSMEYER, W. W.; HEGE, J. H.; THEIL, G. B.; WILSON, W. R. Calcium and phosphorus metabolic studies in triiodothyronine-induced hypermetabolism. The American Journal of the Medical Science, v. 259, n. 4, p. 282-291, 1970.

24 LOUZADA, M. J. Q. Otimização da técnica de densitometria óptica em imagens radiográficas em peças ósseas - estudo "in vitro". 1994. 191 f. Tese (Doutorado) - Faculdade de Engenharia Elétrica, Universidade Estadual de Campinas, Campinas, 1994.

25 VULCANO, L. C. Determinação e padronização dos valores normais da densidade mineral óssea (DMO) do carpo acessório de eqüinos em crescimento da raça Puro Sangue Inglês (PSI) por meio da densitometria óptica radiográfica. 2001. 52 f. Tese (Livre Docência) - Faculdade de Medicina Veterinária e Zootecnia, Universidade Estadual Paulista, Botucatu, 2001. 